\title{
Influence of Cooling Rate and Aging on the Lamellar Microstructure and Fractography of TC21 Titanium Alloy
}

\author{
Hui Shao $\cdot$ Yongqing Zhao $\cdot$ Peng Ge $\cdot$ \\ Weidong Zeng
}

Received: 16 April 2012/Revised: 2 December 2012/ Accepted: 18 December 2012/Published online: 2 February 2013

(C) Springer Science+Business Media New York and ASM International 2013

\begin{abstract}
A new titanium alloy (Ti-5.97Al-2.06Sn$2.02 \mathrm{Zr}-2.96 \mathrm{Mo}-1.25 \mathrm{Cr}-2.08 \mathrm{Nb}-x \mathrm{Si}$, wt. $\%)$ was cooled at different rates to produce a variety of microstructures. Phase and microstructure characterization were performed using LM, SEM, TEM, and XRD. The $\beta$ phase transformed to the $\alpha^{\prime \prime}$ phase upon water quenching. The transformation $\left(\beta \rightarrow \beta_{\text {metastable }}+\alpha\right)$ took place when the cooling rate decreased to the air cooling and furnace cooling rates. After a subsequent aging treatment, both the $\alpha^{\prime \prime}$ and the metastable $\beta$ phase decomposed into $\alpha$ and $\beta$ phases with different morphologies. The tensile and yield strength values depended on the final microstructures and were related to the fractal dimension of the fracture surfaces.
\end{abstract}

Keywords Cooling rate $\cdot$ Aging $\cdot$ Phase $\cdot$ Microstructure $\cdot$ Fractal dimension

\section{Introduction}

$\alpha+\beta$ titanium alloys are widely used as structural components in advanced aerospace applications due to their high strength and high fracture toughness [1]. The range of properties that can be obtained with this alloy is mainly due to the phase transformations that occur when cooling from the high temperature and single phase field. When cooling

H. Shao $(\bowtie) \cdot$ Y. Zhao · W. Zeng

State Key Laboratory of Solidification Processing, Northwestern Polytechnical University, Xi' an 710072, China

e-mail: shaohui-2003@163.com

H. Shao · Y. Zhao - P. Ge

Northwest Institute for Nonferrous Metal Research, Xi'an 710016, China from temperatures above $T_{\beta}$ ( $\beta$ transus temperature) at a high cooling rate, a martensitic reaction can occur. At slow cooling rates, during which the main alloying elements can partition between $\beta$ and $\alpha$ phases, grain boundary $\alpha(\mathrm{GB} \alpha)$ is formed. At intermediate cooling rates, $\alpha$ phase formed in a distinctly different morphology $[2,3]$.

A new $\alpha+\beta$ alloy, referred to as TC21, with the composition Ti-5.97Al-2.06Sn-2.02Zr-2.96Mo-1.25Cr$2.08 \mathrm{Nb}-x \mathrm{Si}$ (wt.\%), has been shown to exhibit high damage tolerance when a lamellar microstructure is present, and provides weight reduction, long service life, and high reliability in aircraft applications [4]. Recently, a variety of studies on the phase transformation [5-7], thermomechanical processes $[8,9]$ and thermohydrogen treatment [10] of this alloy have been performed. However, the effect of the lamellar microstructure on mechanical properties of this alloy has not been thoroughly investigated. The purpose of this study, therefore, is to investigate the relationship between phase transformation and fracture behavior of TC21 alloy, focusing on the influences of cooling rate and aging on the microstructure and tensile properties.

\section{Experimental}

TC21 titanium alloy was prepared by consumable electrode arc melting and forged at $1243 \mathrm{~K}$. The $\beta$ transus temperature of the alloy was about $1223 \mathrm{~K}$. Tensile specimens were heat-treated at $1273 \mathrm{~K}$ for $1 \mathrm{~h}$ followed by cooling at one of three different rates: water quench (WQ: $118 \mathrm{~K} / \mathrm{s}$ ), air cooling (AC: $80 \mathrm{~K} / \mathrm{min}$ ), or furnace cooling (FC: $2 \mathrm{~K} / \mathrm{min}$; cooled to $1073 \mathrm{~K}$ and then air cooled to room temperature). Aging treatments were carried out at $823 \mathrm{~K}$ for $4 \mathrm{~h}$. Specimens for microscopy were sectioned, mounted, polished, and etched with a solution of $1 \mathrm{HF}+2 \mathrm{HNO}_{3}+5 \mathrm{H}_{2} \mathrm{O}$. 
X-ray diffraction (XRD) analysis was conducted on finely polished specimens to determine the lattice spacing and to identify the phases present. Tensile tests were performed on cylindrical specimens with a diameter of $5 \mathrm{~mm}$ and a $30 \mathrm{~mm}$ gage length. Thin foils for transmission electron microscopy (TEM) were prepared in a twin jet electropolishing unit with an electrolyte of $6 \%$ perchloric acid, $60 \%$ methanol, and $34 \% n$-butyl alcohol at a temperature ranging from 243 to $253 \mathrm{~K}$.

\section{Results and Discussion}

\section{X-ray Diffraction}

The XRD patterns for specimens with cooling rates ranging from FC to WQ are shown in Fig. 1. For the slow cooling rate conditions (FC and $\mathrm{AC}$ ), the microstructure consisted mainly of $\alpha$ and $\beta$ phases (Fig. 1a, b), which are formed by a diffusion transformation. The $(100)_{\alpha}$ and $(101)_{\alpha}$ peaks are broader in the AC condition than in the FC condition, likely due to a refinement of $\alpha$ phase under the faster cooling condition (discussed further in a subsequent section). The martensite phase $\left(\alpha^{\prime \prime}\right)$ is a product of the water quench (Fig. 1c). The $b$ value of $\alpha^{\prime \prime}(a=2.95 \AA$, $b=4.964 \AA, c=4.686 \AA$, orthorhombic structure) is bigger than that of $\alpha$ phase $(a=b=2.95 \AA, c=4.686 \AA$, hexagonal structure). Therefore, the (100) and (101) diffraction peaks of $\alpha^{\prime \prime}$ phase are split as compared with the diffraction peaks of $\alpha$ phase (Fig. 1a) [6]. After aging treatment, XRD diffraction patterns (Fig. 2) show that peaks for $\alpha$ and $\beta$ phases were observed for all three cooling rates.

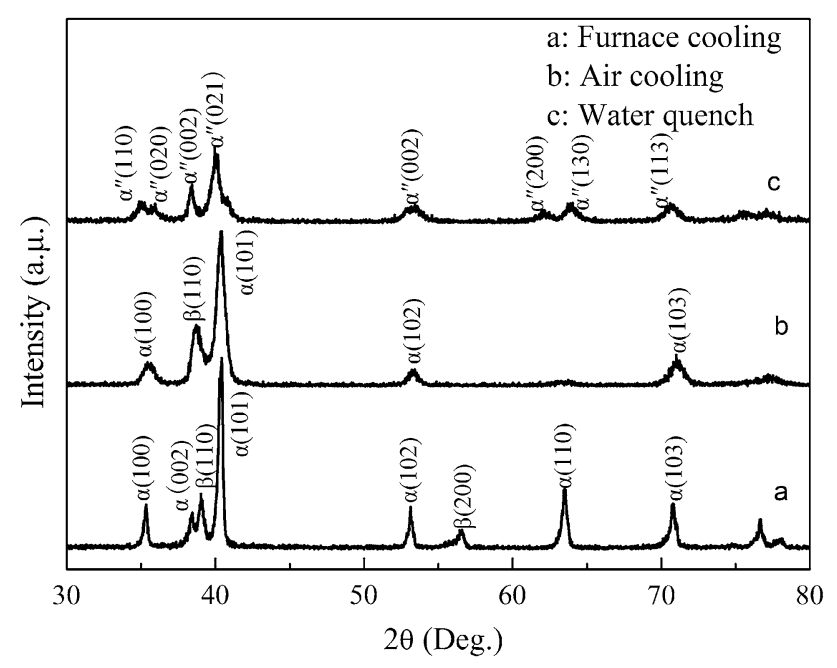

Fig. 1 XRD patterns of three specimens with different cooling conditions. a Furnace cooling, b air cooling, and $\mathbf{c}$ water quench

\section{Microstructure}

The microstructures that resulted from different cooling rates are shown in Fig. 3. For the FC condition, the typical colony microstructure containing several variants of $\alpha$ lath is formed (Fig. 3a). The $\alpha$ phase has three sides [11]: broad face $\left((1 \overline{1} 00)_{\alpha}\left\|(11 \overline{2})_{\beta}, \quad[11 \overline{2} 0]_{\alpha}\right\|[111]_{\beta}\right)$, side face $\left((0001)_{\alpha}\left\|(1 \overline{1} 0)_{\beta},[11 \overline{2} 0]_{\alpha}\right\|[111]_{\beta}\right)$ and edge face (incoherent interface). $\alpha$ phase is expected to grow quickly along the side face due to the low interfacial energy of certain atomic planes. In addition, for the furnace cooling condition, the $\alpha$-phase-free region (molybdenum content, 3-6 wt.\%) is formed due to the low diffusivity of molybdenum which is $1 / 6$ of that for aluminum and vanadium [12]. GB $\alpha$ for the specimen subjected to furnace cooling are observed to be of two types: Type 1, having a zig-zag appearance (Fig. 3b), and Type 2, having a smoother appearance, as shown in Fig. 3c. The type 1 zig-zag boundary layer is consistent with results reported by Ohmori et al. [13] who have proposed that they result from separate heterogeneous nucleation and growth events on prior $\beta$ grain boundary, with each growing $\alpha$ plate maintaining a Burger's relationship with its parent $\beta$ matrix.

With an increase of the cooling rate, $\alpha$ lath may not grow into the entire grain. Consequently, a basket-weave microstructure is formed in the middle of grain (Fig. 3d). Moreover, the thickness of $\alpha$ lath for AC is thinner than that of FC condition. AC condition is considered as a fast cooling method for the TC21 titanium alloy, because it does not produce a lamellar microstructure.

WQ from solution temperature leads to the formation of the $\alpha^{\prime \prime}$ martensite (Fig. 3e). In addition, no $\alpha$ phase

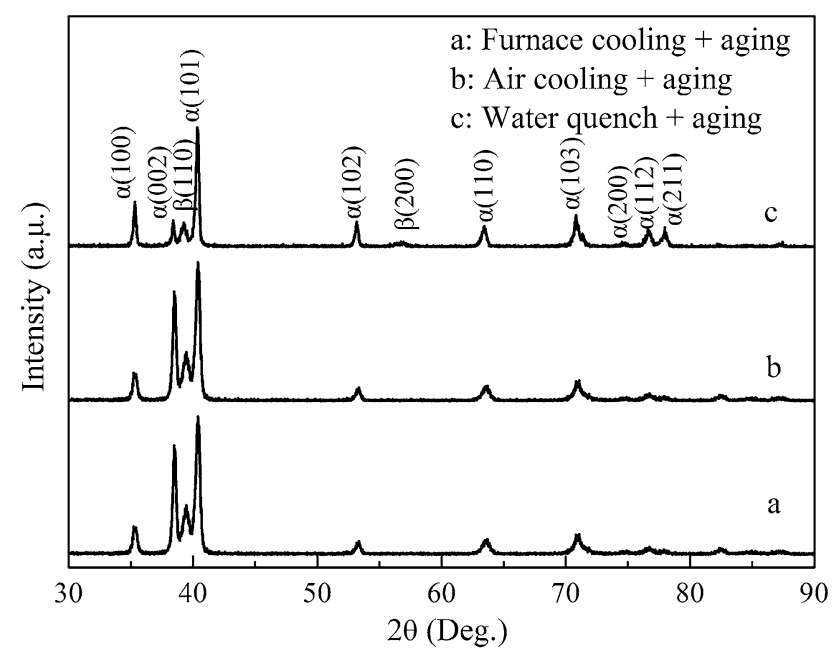

Fig. 2 XRD patterns of three specimens with solution heat treatments after aging treatment. a Furnace cooling + aging, b air cooling + aging, and $\mathbf{c}$ water quench + aging 
Fig. 3 Micrographs for a $1273 \mathrm{~K} / 1 \mathrm{~h} / \mathrm{FC}$ cooled to $1073 \mathrm{~K}$, and air cooled to the room temperature, LM; $\mathbf{b}$ type 1 zig-zag boundary, SEM in (a); c type 2 smooth boundary in (a), SEM; d $1273 \mathrm{~K} / 1$ h/AC, SEM; e $1273 \mathrm{~K} / 1 \mathrm{~h} / \mathrm{WQ}$, TEM; and f stacking faults in the martensite phase, TEM
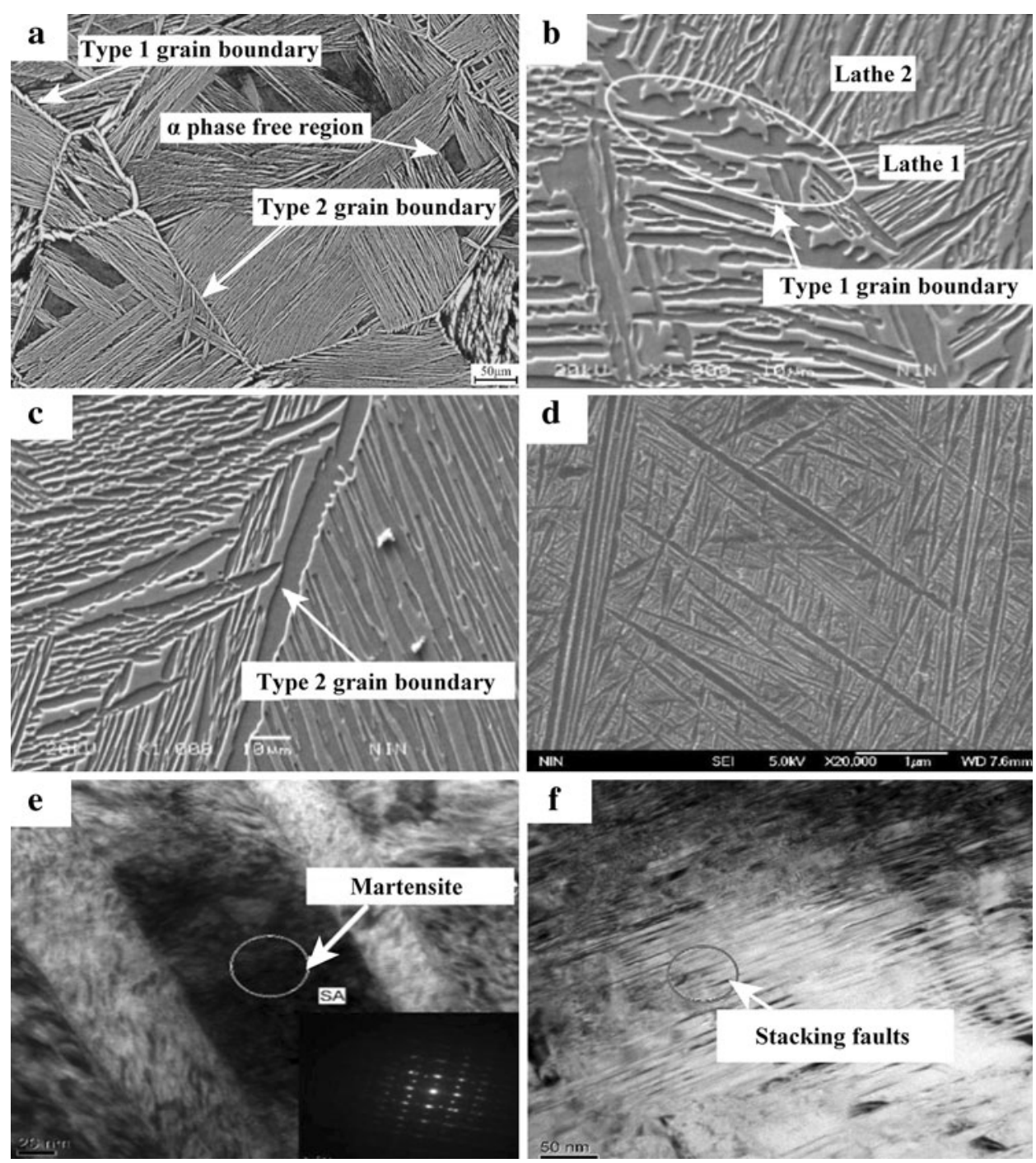

precipitates at the prior $\beta$ grain boundaries were observed and only acicular $\alpha^{\prime \prime}$ plates of several nanometers to several micrometers in thickness are formed. The predominance of dislocations and stacking faults (Fig. 3f) indicates that the relaxation of the invariant strain accompanying $\alpha^{\prime \prime}$ transformation is primarily accomplished by formation of perfect and partial dislocations.

Aging heat treatment was performed at $823 \mathrm{~K}$ for $4 \mathrm{~h}$. The microstructures of as-aged samples are shown in Fig. 4. For the FC condition, $\alpha$ phase plate is observed in transformed $\beta$ (Fig. 4a, b). As the cooling rate decreases from $\mathrm{FC}$ to $\mathrm{AC}$, fine, nanometer-scale $\alpha$ particles precipitate (Fig. 4c, d). The decomposition from martensite into $\alpha$ and $\beta$ phase is shown in Fig. 4(e). These results are in agreement with the XRD results shown in Fig. 2. They demonstrate that the initial cooling rate can affect the microstructure of the as-aged samples.

\section{Method for Fractal Dimension Measurement}

Quantitative fractography is a useful technique for relating the mechanical properties of materials to the fracture mode. The concept of fractal dimension, used to describe irregular surfaces with a self-similar nature, provides a basis for the quantitative characterization of the tortuosity of fracture surfaces [14].

Hilders et al. [15] reported that both yield strength and ultimate tensile strength decreased with increasing fractal dimension of the fracture surface for a duplex stainless steel tested at room temperature. To determine if a similar relationship exists for TC21 titanium alloy, three SEM 
Fig. 4 Dark-field TEM image and the corresponding SADP for secondary $\alpha$ phase at different conditions a and $\mathbf{b} 1000{ }^{\circ} \mathrm{C} / 1 \mathrm{~h} /$ $\mathrm{FC}+550{ }^{\circ} \mathrm{C} / 4 \mathrm{~h} / \mathrm{AC}, \mathrm{c}$ and d $1000{ }^{\circ} \mathrm{C} / 1 \mathrm{~h} / \mathrm{AC}+550{ }^{\circ} \mathrm{C} /$ $4 \mathrm{~h} / \mathrm{AC}$; bright-field TEM image for decomposition of martensite phase at the condition e $1000{ }^{\circ} \mathrm{C} / 1 \mathrm{~h} /$ $\mathrm{WQ}+550{ }^{\circ} \mathrm{C} / 4 \mathrm{~h} / \mathrm{AC}$

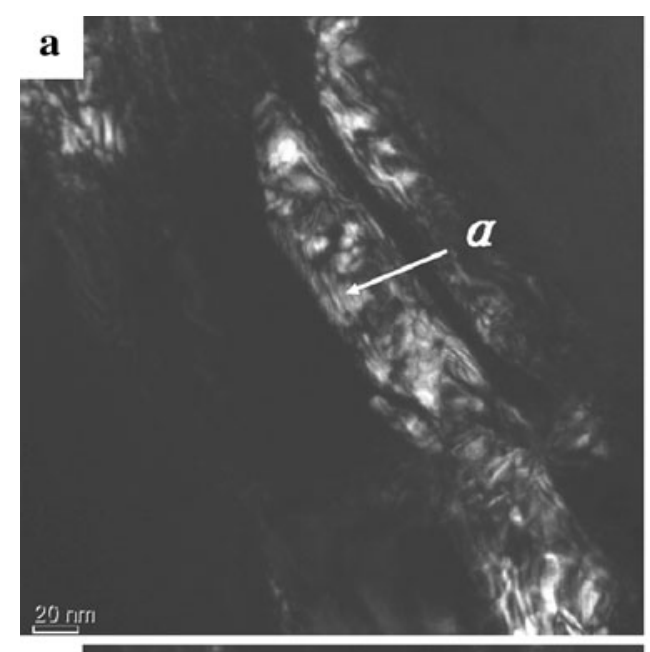

\section{b}
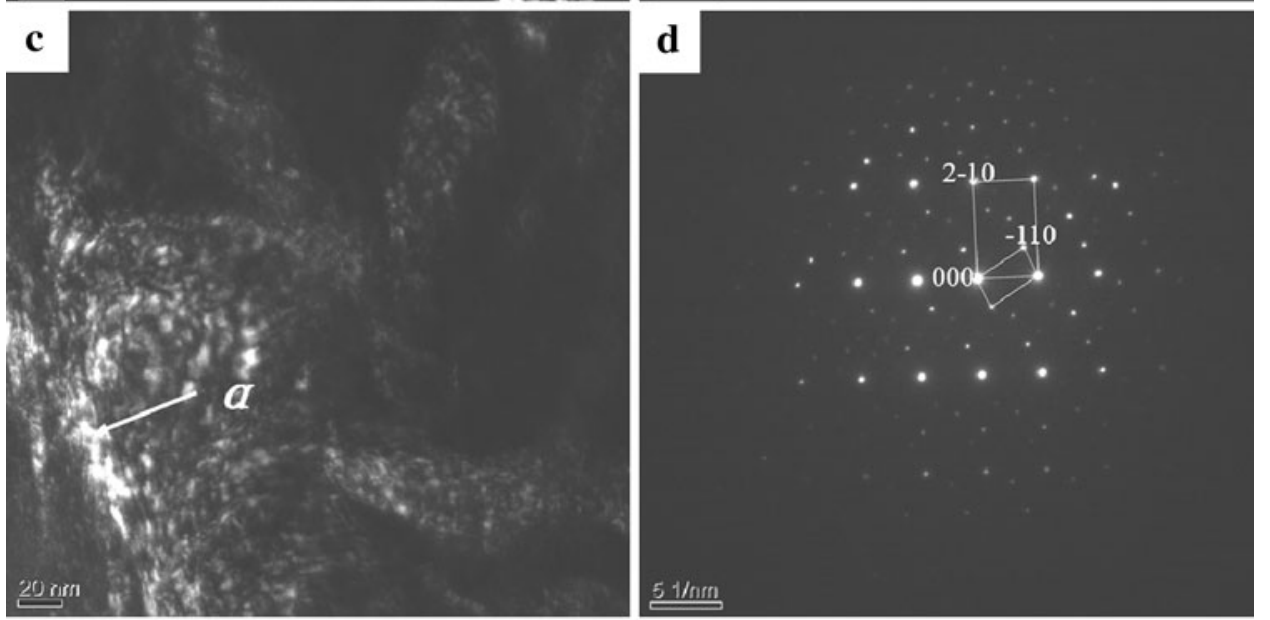

\section{e}

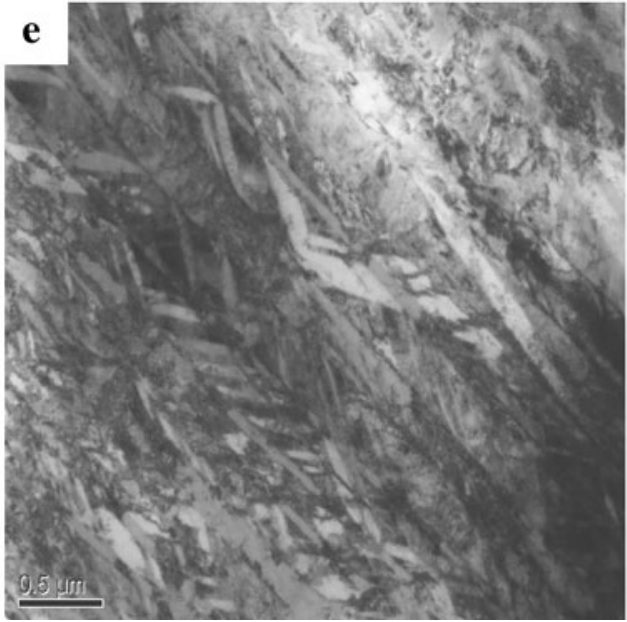

images are taken at different positions on the fracture surface. The images are analyzed after converting them into a digital elevation using a Matlab fractal procedure. The original and threshold fractography images for the AC condition are shown in Fig. 5(a) and (b), respectively. Fractal dimensions of threshold images are determined via measurements of box count $(n(r))$ vs. box size $(r)$ [16] (Fig. 6), utilizing the following relationship:

$D=-d[\ln (n(r)) / \ln (r)] / \mathrm{d} r$,

where $D$ is the fractal dimension and $r$ is the length of a segment. The tensile properties for TC21 after solution and 
Fig. 5 Fracture surface features observed in the AC condition a the original SEM image and b the threshold SEM image
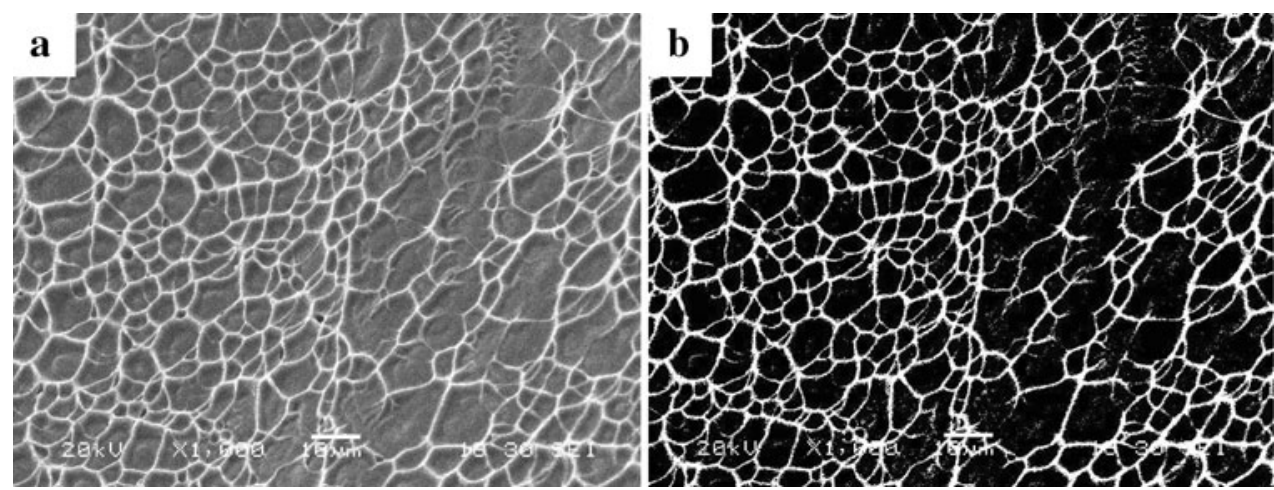

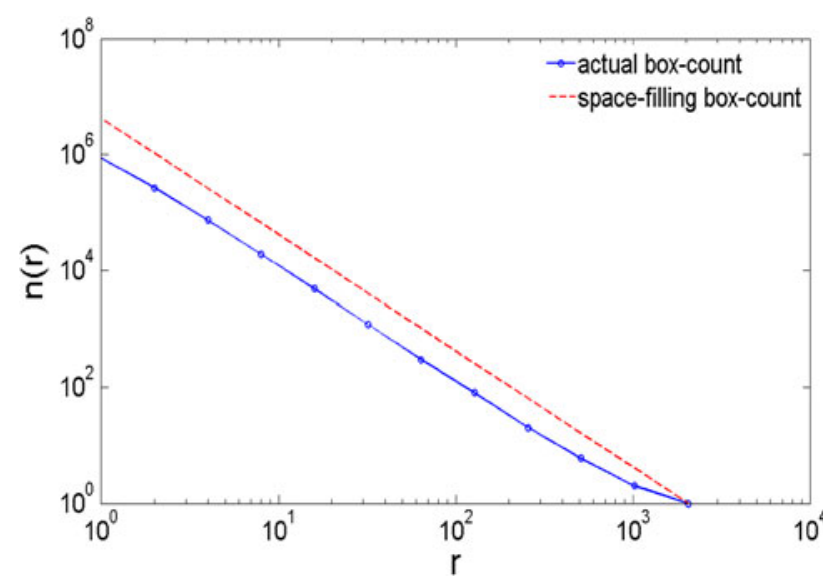

Fig. 6 A type plot of the box count $(n(r))$ vs. box size $(r)$ for the specimen subject to solution with furnace cooling. The red dotted line shows the scaling $n(r)=r^{-2}$ for comparison. The discrepancy between the two curves indicates possible fractal behavior

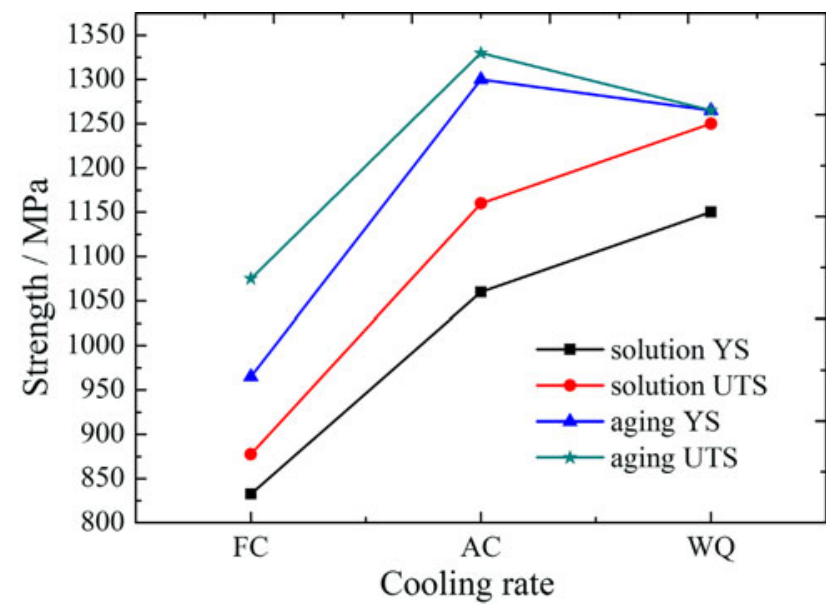

Fig. 7 Curve of the strength vs. cooling condition for the specimen. It could be seen that strength (YS and UTS) for solution condition is bigger than that after aging

solution + aging treatments are shown in Fig. 7. Strength (yield strength, YS and ultimate tensile strength, UTS) increases with increasing cooling rate. The relationship

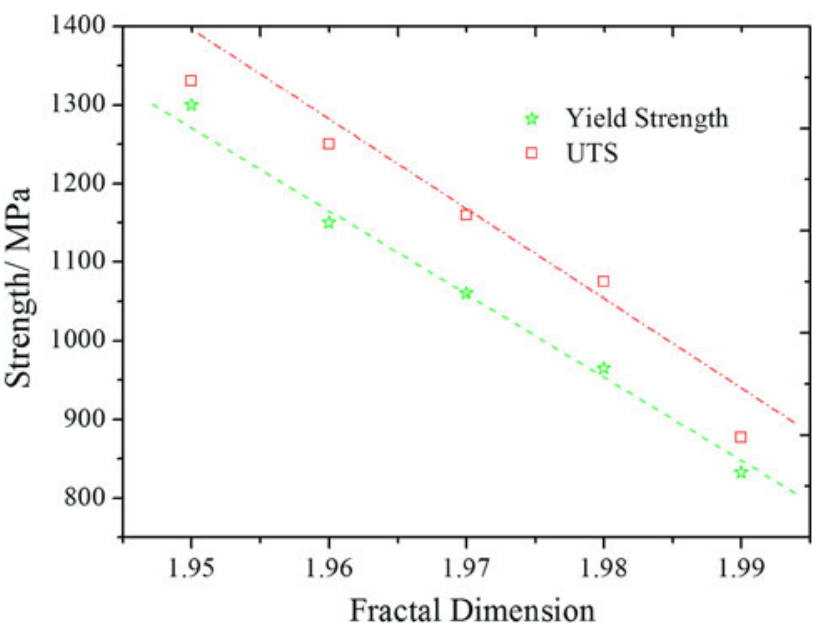

Fig. 8 The relationship between strength and average in fractal dimension of fracture surfaces for TC21 alloy

between the strength and the average fractal dimension of fracture surfaces is shown in Fig. 8. This plot indicates that the tensile strength decreases with increasing fractal dimension. Typical fracture surfaces of the tensile specimens are shown in Fig. 9. Compared with the FC condition (Fig. 9a), the AC condition appears to exhibit a lesser degree of tear ridge formation (Fig. 9b), although the fracture modes for both FC and AC are still ductile with dimpled rupture. The fracture surface of the AC specimen consists of dimples with some cleavage-like facets (step), and the strength (UTS, $1330 \mathrm{MPa}$ ) for this condition is higher than that of the FC condition (UTS, $1075 \mathrm{MPa}$ ). For the WQ condition, (Fig. 9c), the fracture mode is more of cleavage cracking (river pattern) in conjunction with some dimple formation, thus resulting in a higher strength compared to the other two conditions. This is attributed to the presence of martensite arising from the water quench. As a result, the variation in the strength with fractal dimension is primarily attributed to the variation in the fracture surface roughness or fracture mode, caused by varying heat treatment conditions. 
Fig. 9 SEM micrographs of the test specimens at different conditions. a Furnace cooling + aging, $\mathbf{b}$ air cooling + aging, and $\mathbf{c}$ water cooling + aging
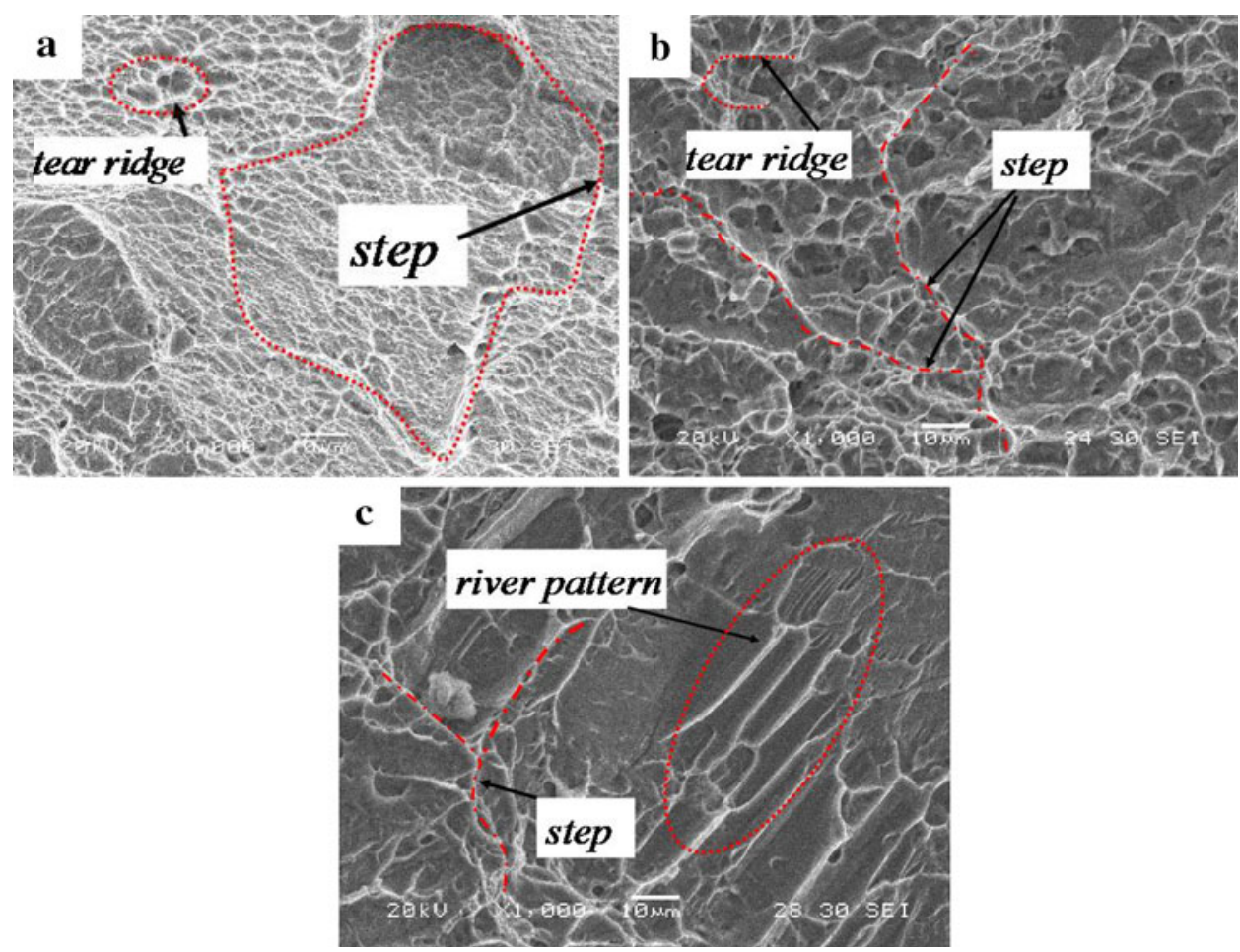

\section{Conclusions}

TC21 titanium alloy was cooled from the $\beta$ phase field at different rates, followed by an aging heat treatment to obtain different phases and microstructures. Tensile tests of the as-cooled and as-aged material were performed. The following results were obtained:

- Morphologies of both GB $\alpha$ and $\alpha$ lamellar were dependent on cooling rates, with GB $\alpha$ existing in one of two types: zig-zag or smooth boundaries.

- $\quad \alpha^{\prime \prime}$ decomposed into $\alpha$ phase and $\beta$ phase after aging at $823 \mathrm{~K}$ for $4 \mathrm{~h}$, while the precipitated $\beta$ phase was not decomposed.

- A relationship between the strength of the alloy and the fractal dimension of the fracture surface was identified. Strength decreases with an increase in fractal dimension due to a change in fracture mode.

Acknowledgments The authors would like to thank Dr. Yi Yang, Kaixuan Wang, Pengwei Wang and Di Shan for their assistance in the experiments. The present investigation was financially supported by NIN in China.

\section{References}

1. G. Lütjering, Influence of processing on microstructure, mechanical properties of $(\alpha+\beta)$ titanium alloys. Mater. Sci. Eng. A243, 32 (1998)
2. S.M.C. van Bohemen, J. Sietsma, S. van der Zwaag, Experimental observations elucidating the mechanisms of structural bcc-hcp transformations in $\beta$-Ti alloys. Phys. Rev. B74, 134114 (2006)

3. S.M.C. vanBohemen, A. Kampa, R.H. Petrov, L.A.I. Kestens, J. Sietsma, Nucleation and variant selection of secondary $\alpha$ plates in a $\beta$ Ti alloy. Acta Mater. 56, 5907 (2008)

4. H.L. Qu, Y.G. Zhou, L. Zhou, Y.Q. Zhao, W.D. Zeng, Relationship among forging technology, structure and properties of TC21 alloy bars. Trans. Nonferrous Met. Soc. China 15, 1120 (2005)

5. Y.H. Fei, L. Zhou, H.L. Qu, Y.Q. Zhao, C.Z. Huang, The phase and microstructure of TC21 alloy. Mater. Sci. Eng. A494, 166 (2008)

6. Y.H. Wang, H.C. Kou, H. Chang, Z.S. Zhu, F.S. Zhang, J.S. Li, L. Zhou, Influence of solution temperature on phase transformation of TC21alloy. Mater. Sci. Eng. A 508, 76 (2009)

7. B. Tang, H.C. Kou, Y.H. Wang, Z.S. Zhu, F.S. Zhang, J.S. Li, Kinetics of orthorhombic martensite decomposition in TC21 alloy under isothermal conditions. J. Mater. Sci. 47, 521 (2012)

8. Y. Zhu, W. Zeng, Y. Sun, F. Feng, Y. Zhou, Characterization of hot deformation behavior of as-cast TC21 titanium alloy using processing map. Mater. Sci. Eng. A528, 1757 (2011)

9. L.R. Wang, Y.Q. Zhao, L. Zhou, Effect of hot rolling on the structure of TC21 alloy with acicular alpha. Mater. Manuf. Processes 2, 154 (2012)

10. X. Wang, Y. Zhao, Y. Wang, H. Hou, W. Zeng, Kinetics of hydrogen absorption/desorption in TC21 alloy. J. Alloys Compd. 490, 562 (2010)

11. S. Furuhara, S. Takagi, H. Watanabe, T. Maki, Crystallography of grain boundary $\alpha$ precipitates in a $\beta$ titanium alloy. Metall. Mater. Trans. A27, 1635 (1996)

12. S.L. Semiatin, T.M. Lehner, J.D. Miller, R.D. Doherty, D.U. Furrer, Alpha/beta heat treatment of a titanium alloy with a nonuniform microstructure. Metall. Trans. A38, 910 (2007) 
13. Y. Ohmori, K. Nakai, H. Ohtsubo, M. Tusnofuri, Formation of Widmanstatten alpha structure in a Ti-6Al-4V alloy. Metall. Trans. 35, 238 (1994)

14. D. Stoyan, H. Stoyan, Fractals, random shapes and point fields: method of geometrical statistics (Wiley, Chichester, 1994)
15. O.A. Hilders, M. Ramos, N.D. Peña, L. Sáenz, Fractal geometry of fracture surfaces of a duplex stainless steel. J. Mater. Sci. 4, 5739 (2006)

16. C.S. Pande, L.R. Richards, S. Smith, Fractal characteristics of fractured surfaces. J. Mater. Sci. 6, 295 (1987) 